\title{
STRATEGI PELAYANAN PRIMA BAGI PELANGGAN VILLA AIR BALI BOUTIQUE
} RESORT AND SPA

\author{
Oleh \\ Anak Agung Sasmita Dewi ${ }^{1)}$, Budi Susanto ${ }^{2)}$ \& I Putu Budiarta ${ }^{3)}$ \\ 1,2,3 Politeknik Negeri Bali \\ 1 budipnb@yahoo.com
}

\begin{abstract}
Abstrak
Penelitian ini dilatarbelakangi oleh rasa ingin tahu penulis terhadap respon pelanggan Villa Air Bali Boutique Resort and Spa dari segi loyalitas pelanggan. Hal ini dikarenakan Villa Air Bali Boutique Resort and Spa memiliki pelanggan yang loyal terhadap pelayanan yang diberikan meskipun di Bali khususnya daerah Seminyak juga banyak terdapat villa resort yang menawarkan pelayanan baik dengan harga lebih murah. Tujuan penelitian ini adalah untuk mengetahui strategi pelayanan prima terhadap loyalitas pelanggan. Teknik pengambilan sampel menggunakan non probability sampling dengan jenis purposive sampling. Responden dalam penelitian ini berjumlah 100 responden. Analisis yang digunakan dalam penelitian adalah analisis kuantitatif dengan menggunakan software SPSS versi 17.0 for Windows, di mana sebelumnya dilakukan uji validitas, reliabilitas, analisis regresi berganda, uji t, uji F, dan koefisien determinasi berganda terlebih dahulu. Hasil penelitian ini menunjukkan bahwa pelayanan prima (X1) dan harga (X2) secara parsial maupun simultan bisa meningkatkan loyalitas pelanggan $(\mathrm{Y})$.
\end{abstract}

Kata Kunci: Pelayanan Prima, Harga \& Loyalitas Pelanggan.

\section{PENDAHUALUAN}

Pada saat ini, memasuki era globalisasi semakin banyak kecanggihan teknologi yang terus tercipta setiap tahunnya yang berguna untuk membantu segala aktivitas manusia.Perkembangan teknologi yang pesat ini dimanfaatkan sebaik-baiknya oleh manusia untuk mendatangkan keuntungan disetiap penggunaan teknologi tersebut.

Dengan besarnya kemajuan teknologi saat ini, semakin banyak perusahaan yang memanfaatkannya untuk memenangkan persaingan yang terjadi dipasaran. Perusahaan berorientasi pada keuntungan, akan tetapi dengan banyaknya kompetitor menjadikan perusahaan harus lebih kompetitif di dalam mengejar keuntungan. Perusahaan menyadari bahwa untuk memenangkan persaingan, perusahaan dituntut untuk memberikan kepuasan kepada pelanggan dengan menyediakan produk dan jasa yang berkualitas dengan harga bersaing.

Pelayanan jasa khususnya dibidang pariwisata setiap tahunnya mengalami persaingan yang semakin kompetitif dengan http://ejurnal.binawakya.or.id/index.php/MBI munculnya pesaing baru dan juga inovasi-inovasi baru yang berfokus pada pemenuhan kebutuhan konsumen. Dewasa ini, perusahaan jasa khususnya di sektor pariwisata tidak hanya bersaing di dalam memasarkan produk, jasa dan juga harga, tetapi perbaikan dari segi pemberian layanan terbaik kepada pelanggan juga menjadi hal yang diperhatikan untuk mencapai loyalitas pelanggan dalam jangka panjang.

Jenis usaha yang bergerak di bidang pariwisata salah satunya adalah akomodasi. Menurut SK Menteri Pariwisata No. 37/PW.304/MPT/86, yang disebut akomodasi adalah suatu tempat penginapan yang dilengkapi pelayanan lainnya seperti layanan makan dan minum.

Pada saat ini akomodasi tidak hanya menawarkan layanan makanan dan minuman tetapi juga layanan lain seperti layanan antar jemput. Kondisi demikian membuat pelanggan dihadapkan pada berbagai alternatif pilihan pembelian dalam rangka memenuhi kebutuhannya.

Vol.13 No.10 Mei 2019 
Persaingan yang terjadi di industri pariwisata khususnya akomodasi semakin ketat. Perusahaan dituntut untuk memberikan pelayanan yang prima kepada pelanggan dan juga harga yang bersaing kepada pelanggan. Pelayanan prima yang diberikan oleh perusahaan akan meningkatkan kepercayaan para pelanggan.

Villa Air Bali Boutique Resort and Spa sebagai salah satu penyedia layanan akomodasi selama 11 tahun, berkomitmen di dalam memberikan pelayanan terbaik kepada tamu dan terus berbenah agar mampu menyesuaikan keinginan dan juga kebutuhan tamu yang menginap.

Sehubungan dengan latar belakang yang telah diuraikan diatas, maka rumusan penelitian ini adalah apakah strategi pelayanan prima bisa meningkatkan loyalitas pelanggan di Villa Air Bali Boutique Resort and Spa?

\section{LANDASAN TEORI}

\section{Pengertian Villa}

Berikut ini adalah beberapa pengertian mengenai villa dari berbagai sumber, yaitu: kata villa dalam bahasa Inggris memiliki arti yaitu rumah kecil yang berada dekat ataupun jauh dan pinggiran kota. (Encyclopedia Britannic, 1961 : 152). Di Amerika Serikat, kata villa dikenal sebagai sebuah pengembangan real estate yang secara umum mengacu pada rumah atau tempat kediaman yang mewah (Encyclopedia Britannic, 1961 : 152). Sementara dalam kamus bahasa Indonesia dikatakan bahwa villa adalah sebuah rumah mungil di luar kota atau di pegunungan yang merupakan rumah peristirahatan yang hanya digunakan pada waktu liburan (Kamus Bahasa Indonesia, 1992).

\section{Pengertian Resort}

Berikut ini adalah beberapa pengertian mengenai resort dari berbagai sumber, yaitu: Resort adalah suatu perubahan tempat tinggal untuk sementara bagi seseorang di luar tempat tinggalnya dengan tujuan antara lain untuk mendapatkan kesegaran jiwa dan raga serta hasrat ingin mengetahui sesuatu. Dapat juga dikaitkan dengan kepentingan yang berhubungan dengan kegiatan olah raga, kesehatan, konvensi,

\section{Vol.13 No.10 Mei 2019}

keagamaan serta keperluan usaha lainnya (Dirjen Pariwisata, 1988 : 13). Sedangkan Pendit mengatakan bahwa Resort adalah sebuah tempat menginap dimana mempunyai fasilitas khusus untuk kegiatan bersantai dan berolah raga seperti tennis, golf, spa, tracking, dan jogging, bagian concierge berpengalaman dan mengetahui betul lingkungan resort, bila ada tamu yang mau hitchhiking berkeliling sambil menikmati keindahan alam sekitar resort ini. (Pendit, 1999).

Berdasarkan pernyataan diatas, maka dapat disimpulkan bahwa resort adalah sebuah tempat menginap sementara yang digunakan untuk tujuan beristirahat, rekreasi dan untuk kepentingan yang berhubungan dengan kegiatan olah raga, kesehatan, konvensi, keagamaan dan lain-lain serta mempunyai fasilitas khusus untuk menunjang kegiatan bersantai pengunjung.

\section{Pelayanan Prima}

Pelayanan adalah suatu kegiatan atau urutan kegiatan yang terjadi dalam interaksi langsung antara seseorang dengan orang lain atau mesin secara fisik, dan menyediakan kepuasan pelanggan (Barata, 2003:30). Dalam Kamus besar Bahasa Indonesia dijelaskan pelayanan sebagai usaha melayani kebutuhan orang lain. Sedangkan melayani adalah membantu menyiapkan (mengurus) apa yang diperlukan seseorang.

Definisi lain menyebutkan bahwa pelayanan adalah suatu bentuk kegiataan pelayanan yang dilaksanakan oleh intansi pemerintah baik di pusat, di daerah, BUMN, dan BUMD dalam bentuk barang maupun jasa dalam rangka pemenuhan kebutuhan masyarakat sesuai perundang-undangan yang berlaku (KEPMENPAN 81/93). Menurut Daviddow dan Uttal (1989) pelayanan merupakan kegiatan/keuntungan yang ditawarkan oleh organisasi atau perorangan kepada konsumen/customer yang bersifat tidak berwujud dan tidak dapat dimiliki.Dalam pelayanan yang disebut konsumen (customer) adalah masyarakat yang mendapat manfaat dari aktivitas yang dilakukan oleh organisasi atau petugas dari organisasi pemberi layanan (Lukman \& Sugiyanto, 2001: 4).

http://ejurnal.binawakya.or.id/index.php/MBI 
Pelayanan Prima (Service Excellence) dapat dipahami sebagai melayani sebagai melayani lebih dari yang diharapkan, dengan memberikan perhatian kepada waktu, ketepatan, keamanan, kenyamanan, kualitas, biaya, proses, dan kepuasan.

Berdasarkan penjelasan diatas dapat diambil kesimpulan dari definisi pelayanan prima (service excellence) adalah sebuah kepedulian oleh perusahaan terhadap para pelanggan dengan berusaha memberikan pelayanan sebaik mungkin dalam memenuhi harapan dan kebutuhan pelanggan, berdasarkan standard dan prosedur pelayanan untuk mewujudkan kepercayaan pelanggan agar mereka selalu puas, sehingga mewujudkan pelanggan yang memiliki loyalitas tinggi.

\section{Konsep Pelayanan Prima (Service Excellence)}

Keberhasilan dalam mengembangkan dan melaksanakan pelayanan prima tidak terlepas dari kemampuan dalam pemilihan konsep pendekatannya. Konsep pelayanan prima berdasarkan A6 (Barata, 2003; 31), yaitu mengembangkan pelayanan prima dengan menyelaraskan konsep-konsep Sikap (Attitude), Perhatian (Attention), Tindakan (Action), Kemampuan (Ability), Penampilan (Appearance), dan Tanggung jawab (Accountability).

\section{Loyalitas Pelanggan}

Dalam kamus besar Bahasa Indonesia (2001: 603) pengertian loyalitas adalah kepatuhan atau kesetiaan. Menurut Engel (1995: 144), loyalitas juga didefinisikan sebagai komitmen mendalam untuk membeli ulang atau mengulang pola prefensi produk atau layanan di masa yang akan datang, yang menyebabkan pembelian berulang merek yang sama atau suatu set merek yang sama, walaupun ada keterlibatan faktor situasional dan upaya-upaya pemasaran yang berpotensi menyebabkan perilaku berpindah merek.

\section{Pengukuran Loyalitas Pelanggan}

Menurut Griffin (2005: 31) loyalitas pelanggan tampaknya merupakan ukuran yang lebih dapat diandalkan untuk memprediksi http://ejurnal.binawakya.or.id/index.php/MBI pertumbuhan penjualandan keuangan.Berbeda dari kepuasan, yang merupakan sikap, loyalitas dapat didefinisikan berdasarkan perilaku membeli. Pelanggan yang loyal adalah orang yang:

1. Melakukan pembelian berulang secara teratur.

Pelanggan yang loyal adalah mereka yang melakukan pembelian barang ataupun jasa secara teratur bahkan mereka akan tetap membeli meskipun harganya mengalami kenaikan.

2. Membeli antar lini produk dan jasa.

Pelanggan yang loyal bukan hanya membeli satu jenis produk atau jasa saja dari sebuah perusahaan, melainkan mereka juga membeli produk ataupun jasa tambahan yang disediakan oleh perusahaan tersebut.

3. Mereferensikan kepada orang lain.

Pelanggan yang loyal selalu ingin mereferensikan suatu produk atau jasa yang digunakannya kepada orang lain, baik kepada teman maupun saudara. Mereka selalu berusaha mempengaruhi orang lain untuk menggunakan produk atau jasa yang sama dengan selalu menceritakan kelebihan produk atau jasa yang dia gunakan sampai orang tersebut mencoba menggunakannya.

4. Menunjukkan kekebalan terhadap tarikan dari pesaing.

Para pelanggan yang loyal selalu menolak apabila ditawari produk atau jasa dari perusahaan lain (pesaing).Mereka sudah memiliki kecintaan tersendiri terhadap produk atau jasa yang telah digunakan.

\section{METODE PENELITIAN}

\section{Lokasi Penelitian}

Villa Air Bali Boutique Resort and Spa merupakan salah satu akomodasiyang berlokasi di daerah Seminyak.Villa Air Bali Boutique Resort and Spa menawarkan villa-villa dengan kolam renang pribadi, yang berjarak 5 menit berkendara dari Seminyak Square dan kawasan

Vol.13 No.10 Mei 2019

\section{Open Journal Systems}


perbelanjaan.Resort ini menawarkan kelas memasak, latihan yoga, dan Wi-Fi gratis di semua villa.Masing-masing villa terletak di tengah taman tropis, dan memiliki ruang tamu dengan ruang makan terbuka. Villa Air Bali juga menyediakan pelajaran membuat perhiasan dan membuat sabun.

Villa Air Bali Boutique Resort and Spa berlokasi di Jalan Lebak Sari, Br. Taman, 80361 Seminyak, Indonesia. Website: http://www.villaairbali.com.

\section{Identifikasi Variabel}

Variabel penelitian menurut Sugiyono (2016:38) adalah suatu atribut atau sifat atau nilai dari orang, obyek atau kegiatan yang mempunyai variasi tertentu yang ditetapkan oleh peneliti untuk dipelajari dan ditarik kesimpulannya.Variabel dalam penelitian ini terdiri dari variable bebas $(\mathrm{X})$ dan variabel terikat (Y).

Varibel bebas dalam penelitian ini terdiri dari pelayanan Prima $\left(\mathrm{X}_{1}\right)$ dan harga $\left(\mathrm{X}_{2}\right)$. Varibel terikat dalam penelitian ini adalah loyalitas Konsumen (Y)

\section{Definisi Operasional Variabel}

Definisi operasional dalam penelitian ini meliputi :

1. Pelayanan Prima $\left(\mathrm{X}_{1}\right)$

2. Harga $\left(\mathrm{X}_{2}\right)$

3.Loyalitas Pelanggan (Y)

\section{Jenis dan Sumber Data}

Adapun jenis data yang digunakan dalam penelitian ini adalah sebagai berikut:

1. Data Kualitatif

Adapun data kualitatif dalam penelitian ini adalah respon pelanggan terkait pelayanan prima yang diberikan oleh pihak Villa Air Bali Boutique Resort and Spa.

2. Data Kuantitatif

Adapun data kuantitatif yang digunakan didalam penelitian ini adalah harga kamar yang ditawarkan oleh pihak Villa Air Bali Boutique Resort and Spa, jumlah kunjungan tamu yang menginap di Villa Air Bali Boutique Resort and Spa.

Sumber data dapat dibedakan menjadi dua yaitu data primer dan data skunder. Data primer Vol.13 No.10 Mei 2019 merupakan data yang dikumpulkan secara langsung oleh peneliti atau pihak pertama, sedangkan data sekunder merupakan data yang dikumpulkan oleh pihak lain dan dimanfaatkan oleh penelitian untuk kebutuhan penelitian yang dilakukannya.

\section{Metode Pengumpulan Data}
1. Observasi.
2. Wawancara.
3. Kuesioner.

\section{Teknik Analisis Data}

Penelitian ini menggunakan metode sebagai berikut:

1. Uji Validitas

Uji validitas menyatakan bahwa instrumen yang digunakan untuk mendapatkan data dalam penelitian dapat digunakan atau tidak. Menurut Sugiyono (2012:121) menyatakan bahwa valid berarti instrumen tersebut dapat digunakan untuk mengukur apa yang seharusnya diukur. Untuk mencari nilai validitas di sebuah item mengkorelasikan skor item dengan total item-item tersebut. Jika ada item yang tidak memenuhi syarat, maka item tersebut tidak akan diteliti lebih lanjut. Syarat tersebut menurut Sugiyono (2012:133) yang harus dipenuhi yaitu harus memiliki kriteria sebagai berikut:

a. Jika $r \geq 0,3$ maka item-item tersebut dinyatakan valid.

b. Jika $\mathrm{r} \leq 0,3$ maka item-item tersebut dinyatakan tidak valid.

Uji validitas instrumen dapat menggunakan rumus korelasi. Rumus korelasi berdasarkan Pearson Product Moment adalah sebagai berikut :

$$
\begin{gathered}
r_{x y}= \\
\frac{\mathrm{N} \sum \mathrm{xy}-\left(\sum \mathrm{x}\right)(\Sigma \mathrm{y})}{\sqrt{\left(\mathrm{N} \sum \mathrm{x}^{2}-\left(\sum \mathrm{x}\right)^{2}\left(\mathrm{~N} \sum \mathrm{y}^{2}-\left(\sum \mathrm{y}\right)^{2}\right)\right.}}
\end{gathered}
$$$$
\text { ...............(1) }
$$

Keterangan:

$\mathrm{r}_{\mathrm{xy}}=$ Koefisien Korelasi antara variable $\mathrm{X}$ dan variable $\mathrm{Y}$

$\mathrm{N} \quad=$ Banyaknya Sampel

$\Sigma \mathrm{x}=$ Jumlah skor keseluruhan untuk item pertanyaan variabel $\mathrm{x}$

http://ejurnal.binawakya.or.id/index.php/MBI 
$\Sigma \mathrm{y}=$ Jumlah skor keseluruhan untuk item pertanyaan variabel y

$\Sigma \mathrm{x}^{2}=$ Jumlah dari kuadrat nilai $\mathrm{X}$

$\Sigma \mathrm{y}^{2}=$ Jumlah dari kuadart nilai $\mathrm{Y}$

$(\Sigma \mathrm{x})^{2}=$ Jumlah nilai $\mathrm{X}$ kemudian dikuadratkan

$(\Sigma \mathrm{y})^{2}=$ Jumlah nilai $\mathrm{Y}$ kemudian dikuadratkan

2. Uji Reliabilitas

Uji reliabilitas menyatakan bahwa apabila instrument yang digunakan beberapa kali untuk mengukur objek yang sama akan menghasilkan data yang sama. Menurut Sugiyono (2012:122) reliabilitas adalah derajat konsistensi/ keajengan data dalam interval waktu tertentu.Berdasarkan pengertian diatas maka reabilitas dapat dikemukakan sebagai suatu karakteristik terkait dengan keakuratan, ketelitian, dan kekonsistenan.Pengujian reliabilitas kuesioner pada penelitian ini penulis menggunakan metode Alpha Cronbachdengan rumus sebagai berikut:

$r 11=\left[\frac{k}{k-1}\right]\left[1-\frac{\Sigma S i^{2}}{S t^{2}}\right]$.

Keterangan:

r11 = Koefisien Reliabilitas instrument

$\mathrm{k}=$ Jumlah butir pertanyaan

$\Sigma \mathrm{Si}^{2}=$ Jumlah varian butir

$\mathrm{St}^{2}=$ Jumlah varian total

Adapun kriteria untuk menilai reliabilitas instrumen penelitian ini yang merujuk kepada pendapat (Nunnally, 1967 dalam Ghozali, 2007:42) "Suatu konstruk atau variabel dikatakan reliabel jika memberikan nilai Cronbach Alpha> 0,60."

3. Analisis Regresi Berganda

Karena dalam penelitian ini terdapat lebih dari satu variabel bebas yang akan diuji untuk mengetahui pengaruhnya terhadap variabel terikat, maka proses analisis regresi yang dilakukan adalah menggunakan analisis regresi berganda. Menurut Sugiyono (2013:277) mendefinisikan bahwa: "Analisis regresi ganda digunakan oleh peneliti, bila peneliti bermaksud meramalkan bagaimana keadaan (naik turunnya) variabel dependen (kriterium), bila dua atau lebih variabel independen sebagai faktor prediktor dimanipulasinya (dinaik-turunkannya)".

Persamaan regresi berganda untuk dua prediktor yang ditetapkan adalah sebagai berikut:

$$
\begin{aligned}
& Y=\alpha+\beta 1 x 1+\beta 2 x 2+ \\
& e \ldots \ldots \ldots \ldots \ldots \ldots \ldots(3)
\end{aligned}+
$$

Keterangan:

$Y \quad=$ Loyalitas pelanggan

$\alpha \quad=$ Koefesien konstanta

$\beta 1 \beta 2=$ Koefesien regresi

$x 1=$ Pelayanan prima

$x 2=$ Harga

$e=$ Tingkat kesalahan

(error)/Pengaruh faktor lain

4. Uji t

Menurut Ghozali (2013:98), uji statistik t pada dasarnya menunjukkan seberapa jauh pengaruh satu variabel penjelas atau independen secara individual dalam menerangkan variasi variabel dependen. Salah satu cara melakukan uji t adalah dengan membandingkan nilai statistik $t$ dengan baik kritis menurut tabel. Sedangkan menurut Sugiyono (2011:194) uji t digunakan untuk mengetahui masingmasing sumbangan variabel bebas secara parsial terhadap variabel terikat, menggunakan uji masing-masing koefisien regresi variabel bebas apakah mempunyai pengaruh yang bermakna atau tidak terhadap variabel terikat Untuk menguji apakah masing-masing variabel bebas berpengaruh secara signifikan terhadap variabel terikat secara parsial dengan $\alpha=$ 0,05 . Maka cara yang dilakukan adalah:

a. Bila (P-Value) $<0,05$ artinya variabel independen secara parsial mempengaruhi variabel dependen.

b. Bila (P-Value) > 0,05 artinya variabel independen secara parsial tidak mempengaruhi variabel dependen.

5. Uji F 
Menurut Sugiyono (2011:192) uji F digunakan untuk mengetahui apakah secara simultan koefisien variabel bebas mempunyai pengaruh nyata atau tidak terhadap variabel terikat. Untuk menguji apakah masing-masing variabel bebas berpengaruh secara signifikan terhadap variabel terikat secara bersama-sama dengan $\alpha=0,05$. Makacara yang dilakukan adalah:

a. Bila (P-Value) $<0,05$ artinya variabel independen secara simultan mempengaruhi variabel dependen.

b. Bila (P-Value) > 0,05 artinya variabel independen secara simultan tidak mempengaruhi variabel dependen.

6. Koefisien Determinasi

Koefisien determinasi $\left(\mathrm{R}^{2}\right)$ pada intinya mengukur seberapa jauh kemampuan model dalam menerangkan variasi variabel dependen.Nilai koefisien determinasi adalah antara nol sampai satu $\left(0<\mathrm{R}^{2}<\right.$ 1).Nilai $R^{2}$ yang kecil berarti kemampuan variabel-variabel independen dalam menjelaskan variasi variabel dependen sangat terbatas.Nilai yang mendekati satu berarti variabel-variabel independen memberikan hampir semua informasi yang dibutuhkan untuk memprediksi variasi variabel dependen.

$\mathrm{KD}=\mathrm{r}^{2} \times 100 \%$

Keterangan:

$\mathrm{KD}=$ Koefisien Determinasi

$\mathrm{r} \quad=$ Koefisien Korelasi

\section{HASIL DAN PEMBAHASAN}

Dalam penelitian ini, didapatkan hasil bahwa pelayanan prima memiliki pengaruh secara signifikan terhadap loyalitas pelanggan.Hal ini dapat dibuktikan dari hasil uji t dengan hasil bahwa t hitung 4,988 > t tabel 1.98472 (lampiran 9) sehingga hipotesis pertama yang menyatakan bahwa terdapat pengaruh pelayanan prima terhadap loyalitas pelanggan diterima. Dengan demikian, hal ini menunjukkan bahwa semakin baik atau meningkatnya pelayanan prima yang diberikan oleh Villa Air Bali Boutique Resort and
Spa kepada pelanggannya akan semakin meningkat pula loyalitas pelanggan Villa Air Bali Boutique Resort and Spa.

Pelayanan prima yang memiliki pengaruh terhadap loyalitas pelanggan Villa Air Bali Boutique Resort and Spa sejalan dengan pendapat Barata (2003:27) yang menyatakan bahwa pelayanan prima adalah kepedulian kepada pelanggan dengan memberikan layanan terbaik untukmemfasilitasi kemudahan pemenuhan kebutuhan agar mereka selalu loyal kepada perusahaan atau sebuah organisasi.

Pelayanan prima yang diberikan oleh pihak Villa Air Bali memiliki nilai baik dimata para pelanggan. Hal ini dibuktikan dengan hasil analisis regresi linear berganda yang menunjukkan nilai sebesar 0.081(lampiran 7) artinya jika variabel independen lainnya tetap dan variabel pelayanan prima mengalami kenaikan $1 \%$, maka loyalitas pelanggan (Y) akan mengalami kenaikan sebesar 0.081 . Koefisien bernilai positif artinya terjadi hubungan positif antara pelayanan prima dan loyalitas pelanggan, semakin meningkatnya pelayanan prima yang ditawarkan maka semakin naik pula loyalitas pelanggan.

Berdasarkan hasil tanya jawab secara insidental dengan karyawan front office Villa Air Bali, pelayanan prima yang diberikan kepada pelanggan Villa Air Bali memiliki fokus untuk melayani pelanggan secara ramah, membuat pelanggan merasa dihargai, dan melakukan pelayanan yang optimal dan konsisten untuk mencapai kepuasan pelanggan. Pendapat ini diperkuat oleh hasil tanya jawab dengan Bapak Eka selaku Guest Service Manager Villa Air Bai Boutique Resort and Spa yang mengatakan bahwa pelayanan yang diberikan harus maksimal sejak awal kedatangan tamu hingga akhir periode menginap tamu yang berorientasi pada standar layanan yang diterapkan di Villa Air Bali Boutique Resort and Spa. Pelayanan yang baik merupakan pelayanan yang mengutamakan kepuasan tamu dan selalu berusaha untuk memberikan pelayanan yang melebihi harapan tamu sehingga tamu merasa puas dan akhirnya akan melakukan pembelian kembali dimasa yang http://ejurnal.binawakya.or.id/index.php/MBI 
akan mendatang, dimana pemberian pelayanan prima itu sendiri mencakup kemampuan petugas didalam memberikan layanan yang melebihi harapan tamu, sikap petugas didalam merespon berbagai permintaan dan pertanyaan tamu secara jujur, cepat dan tepat, sikap petugas yang selalu melakukan kontak dengan tamu seperti mengucapkan salam dan menyambut tamu dengan senyuman juga menjadi salah satu bentuk pelayanan prima yang diterapkan di Villa Air Bali Boutique Resort and Spa. Hal ini sejalan dengan pendapat Barata (2003:27) yang menyatakan bahwa keberhasilan program pelayanan prima tergantung pada penyelarasan kemampuan, sikap, penampilan, perhatian, tindakan dan tanggung jawab dalam pelaksanaannya.

Dalam penelitian ini didapatkan hasil bahwa harga memiliki pengaruh secara signifikan pula terhadap loyalitas pelanggan. Hal ini dapat dibuktikan dari hasil uji t dengan hasil bahwa $\mathrm{t}$ hitung 2,637 > t table 1,98472 (lampiran 9) sehingga hipotesis kedua yang menyatakan bahwa terdapat pengaruh antara harga dan loyalitas pelanggan diterima. Dengan demikian, hal ini menunjukkan bahwa semakin baik tingkat kesesuaian harga yang diberikan oleh Villa Air Bali Boutique Resort and Spa akan semakin meningkat pula loyalitas pelanggan Villa Air Bali Boutique Resort and Spa.

\section{DAFTAR PUSTAKA}

[1] Arikunto, Suharsimi, 2006. Metodelogi penelitian. Yogyakarta: Bina Aksara

[2] Asih, N.S., Nuridja, I.M. and Zukhri, A., 2016.Pengaruh Pelayanan Prima (Service Excellent) terhadap Kepuasan Pelanggan Salon Agata Singaraja. Jurnal Pendidikan Ekonomi Undiksha, 7(2).

[3] Barata, A.A., 2003. Dasar-dasar pelayanan prima.Elex Media Komputindo.

[4] Griffin, J. 2002. Customer Loyalty Menumbuhkan dan Mempertahankan Kesetiaan Pelanggan. Jakarta: Erlangga.

[5] Irnandha, A., 2016. Pengaruh Kualitas Layanan Terhadap Loyalitas Pelanggan Yang Dimediasi Oleh Kepuasan Pelanggan Jasa Pengiriman Jalur Darat (Studi Kasus http://ejurnal.binawakya.or.id/index.php/MBI
Kepuasan Pelanggan Jne Cabang Hijrah Sagan Yogyakarta). Jurnal Manajemen Bisnis Indonesia (JMBI), 5(6), pp.660-669.

[6] Kartika, Dwi, Syafitri, Dea Ariesta. (tt). Efektivitas Pelayanan Prima (Service Excellence) Terhadap Kepuasan Pelanggan Yang Berdampak Pada Loyalitas Pelanggan Pada Toko Obat Dewi Farma.

[7] Kartika, E.W. and Kaihatu, T.S., 2012. Analisa pengaruh kualitas layanan terhadap loyalitas pelanggan di laundry 5ASEC Surabaya. Jurnal Manajemen Perhotelan, 4(2), pp.45-57.

[8] Kotler, Philip. 2005. Manajamen Pemasaran, Jilid 1 dan 2. Jakarta: PT. IndeksKelompok Gramedia.

[9] Kotler, Philip \& Kevin Lane, Keller. 2012. Marketing Management Edisi 14, Global Edition. New Jersy : Prentice Hall.

[10] Lupiyoadi,R., 2008. Manajemen Pemasaran Jasa. Salemba, Jakarta.

[11]Nisa, K., 2012. Pengaruh Kepuasan Pelayanan, Lokasi, dan Harga Terhadap Kepuasan Pelanggan PT. Pos Indonesia (Persero) Sidoarjo. Jurnal Ilmiah Mahasiswa $F E B, 1(2)$.

[12] Saputra, F.A., Nugraha, H.S. and Widiartanto, W., 2015. Pengaruh Pelayanan Prima Dan Harga Terhadap Loyalitas Pelanggan (Studi Pada Pelanggan Layanan PT. Pos Indonesia Semarang). Jurnal Ilmu Administrasi Bisnis, 4(3), pp.216-223..

[13] Senjaya, V., 2013. Pengaruh Customer Experience Quality Terhadap Customer Satisfaction \& Customer Loyalty Di Kafe Excelso Tunjungan Plaza Surabaya: Perspektif B2C. Jurnal Strategi Pemasaran, 1(1).

[14] Suantari, I.G.A.A.W., 2015. VILLA RESORT DI TULAMBEN KARANGASEM(Doctoral dissertation, Universitas Udayana).

[15] Sugiyono, Prof. Dr., 2016. Metode Penelitian Pendekatan Kuantitatif, Kualitatif dan $R \& D$. Bandung : Alfabeta

[16] Yusup, M. and SUTOPO, S., 2011.Analisis Pengaruh Promosi, Harga, Kualitas Produk Dan Layanan Purna Jual Terhadap Vol.13 No.10 Mei 2019 
Keputusan Pembelian Sepeda Motor Honda

(Studi Kasus pada Mahasiswa Fakultas

Ekonomi Universitas Diponegoro

Semarang). (Doctoral dissertation,

Universitas Diponegoro). 